\title{
Relações e relacionamentos de pessoas LGBT em prisão masculina: Entre normas e limites do dentro e fora da prisão
}

Francisco Elionardo de Melo Nascimento

Universidade Estadual do Ceará, Fortaleza, CE, Brasil

Roberto Marques

Universidade Estadual do Ceará, Fortaleza, CE, Brasil

Maria do Socorro Ferreira Osterne

Universidade Estadual do Ceará, Fortaleza, CE, Brasil

\begin{abstract}
Este artigo discute as normas e os limites estabelecidos na vivência da população LGBT privados de liberdade no Ceará. Ressalta relações de poder e hierarquia baseadas em marcadores de gênero e sexualidade expressos por esses atores em suas relações entre si, com outros presos, visitantes, profissionais e facções. A necessidade de negociação com mediadores de distintas naturezas, no cotidiano prisional, vem impondo dinâmicas dramáticas às pessoas LGBT. Assim, marcações de sexualidade ganham destaque a partir do lugar que a diferença ocupa nas relações sexual-afetivas estabelecidas nas fronteiras entre o dentro e o fora da prisão.
\end{abstract}

Palavras-chave: população LGBT, diferença, sexualidade, prisão, relações de poder/ hierarquia
LGBT Relations and Relationships in Male Prison: Between Standards and Limits of Inside and Out of Prison discusses the norms and limits established in the experience of the LGBT population deprived of freedom in Ceará. It emphasizes power and hierarchy relationships based on gender and sexuality markers expressed by these actors in their relations with each other, with other prisoners, visitors, professionals and factions. The need for negotiation with mediators of different natures in daily prison has been imposing dramatic dynamics on LGBT people. Thus, sexuality markings gain prominence from the place that difference occupies in sexual-affective relationships established on the borders between inside and outside the prison.

Keywords: LGBT population, difference, sexuality, prison, power relations/ hierarchy

\section{Introdução}

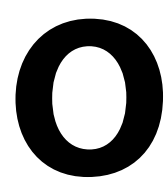

Centro de Execução Penal e Integração Social Vasco Damasceno Weyne (CPIS) é a maior penitenciária do Ceará. Tem capacidade para abrigar 1.016 internos, está localizada na Região Metropolitana de Fortaleza (RMF), município de Aquiraz, e é uma penitenciária integrante do Complexo Penitenciário Estadual de Itaitinga II - integrado também pela Casa de Privação Provisória de Liberdade Professor Clodoaldo Pinto (CPPL II), pela Casa de Privação Provisória de Liberdade Professor Jucá Neto (CPPL III) e pela Casa de Privação Provisória de Liberdade Agente Elias Alves da Silva (CPPL IV). Inaugurada em novembro de 2016, a CPIS está dividida em oito pavilhões e seis galpões construídos com a finalidade de proporcionar trabalho e capacitação profissional para os internos. Ao longo do período de imersão em campo, a unidade abrigava 1.937 pessoas em cumprimento de pena. 
Ao longo de 2016, o sistema penitenciário cearense passou por intensas mudanças em sua organização e estruturação. A visibilidade adquirida pelos grupos criminais a partir das rebeliões ocorridas nas unidades prisionais da RMF, em maio daquele ano, influenciou diretamente a realocação de presos nos presídios do Ceará levando em consideração suas filiações a grupos faccionados.

As facções que atuam dentro e fora dos presídios cearenses são o Primeiro Comando da Capital (PCC), o Comando Vermelho (CV), os Guardiões do Estado (GDE) e a Família do Norte (FDN) (NASCIMENTO, 2017; SÁ e AQUINO, 2018)ํ․ Tensões entre facções, internos e o Estado definiram também a criação de unidades prisionais destinadas a presos não filiados a facções e/ou tidos como "frágeis" e "vulneráveis" pelo Estado (NASCIMENTO, 2018a)².

Ainda em construção no momento da transferência dos presos ${ }^{3}$, a CPIS foi utilizada para abrigar os artigos errados ${ }^{4}$ ou equiparados, ou seja, os presos que respondem pena privativa de liberdade por crimes sexuais, prescritos na Lei Maria da Penha, homicídio de mulheres e outras pessoas tidas como indefesas na lógica do crime $^{5}$. Para lá foram encaminhadas ainda as bichas ${ }^{6}$, igualmente rejeitadas no convívio da Babilônia ${ }^{7}$.

Após sua inauguração em novembro de 2016, a CPIS passou a abrigar a massa carcerária presos não filiados às facções —, sendo reservados dois pavilhões para os presos LGBT e os duzentos $^{8}$, que dividem o mesmo espaço nas celas.

Entre 2016 e 2018, realizamos uma pesquisa etnográfica que discutiu o aprisionamento de travestis no Ceará (Idem). A entrada e a permanência em campo foram moduladas pela dupla ocupação do primeiro autor deste texto como agente penitenciário e pesquisador. As discussões foram desenvolvidas a partir de intensas interlocuções com pessoas LGBT dentro e fora do sistema prisional, funcionários, prestadores de serviços e administradores do sistema prisional cearense, militantes, entre outros. A pesquisa percorreu, portanto, cenários diversos, tecidos desde o percurso profissional do pesquisador até o trabalho de campo. A análise do conjunto do material etnográfico relevou que a dinâmica institucional e das facções interfere diretamente na vida das travestis privadas de liberdade, regulando fluxos de objetos e signos performatizados (BUTLER, 2013) na construção de suas travestilidades. Foram também tematizadas as formas de manutenção dos relacionamentos com companheiros da liberdade ${ }^{9}$ mediante esse contexto moral complexo, formado por múltiplos mediadores.

Como recorte da pesquisa citada, este artigo pretende discutir normas e limites das relações e dos relacionamentos de LGBTs entre o dentro e o fora das prisões no Ceará. Remeter-nos-emos aqui às vivências de pessoas LGBT privadas de liberdade na CPIS, ao tratamento direcionado a esse público na unidade referenciada e às relações e aos relacionamentos que extrapolam os muros do presídio por meio de suas porosidades (GODOI, 2015) ${ }^{10}$. Com isso, pretendemos pôr em 
discussão as relações de poder e hierarquia que circulam e são atravessadas por marcadores de diferença tais como, gênero, sexualidade e classe ${ }^{11}$.

Em texto inaugural dos estudos de sexualidade, Peter Fry (1982) interpreta a existência de dois modelos classificatórios das interações sexuais entre homens no Brasil. A existência de dois modelos paralelos estaria amparada pelas diferenças de origem, classe, raça e localização espacial presentes em nosso país. O modelo classificatório clássico da homossexualidade entre homens, baseado no gênero e na posição assumida durante a interação sexual, foi denominado como hierárquico-popular. A este se contrapunha o modelo igualitário-moderno, utilizado por gays de classe média urbana intelectualizada. Ao opor masculinidade/atividade sexual e feminilidade/passividade sexual para pensar a sexualidade no Brasil, o autor nos conduz a um jogo de imaginação que estabelece classificações a partir de oposições ${ }^{12}$.

As leituras contemporâneas críticas ao texto de Fry permitem comparar universos homo e heterossexuais a partir do lugar que a diferença ocupa nas relações que envolvem o afeto e o desejo. Simões, França e Macedo (2010) definem a marcação da diferença como componentechave de qualquer sistema classificatório. Dessa maneira, "pessoas, objetos e comportamentos ganham sentido - vale dizer, são socialmente produzidos - por meio das diferentes posições em um sistema classificatório" (SIMÕES, FRANÇA e MACEDO, 2010, p. 40). Por meio da classificação, indivíduos tornam-se sujeitos e atores sociais, apropriam-se ou são levados a reconhecerem a si mesmos a partir de determinadas identidades.

Propomo-nos aqui, portanto, a refletir sobre as relações e os relacionamentos entre o dentro e o fora da prisão e de que modo e em que condições essas diferenças, que informam e constroem relações de poder e hierarquia, são agenciadas por determinados sujeitos no cotidiano do cárcere.

A propósito disso, o lugar que a diferença ocupa nas relações que envolvem afeto e desejo, poder e hierarquia nos remete à importância do debate sobre a igualdade e/ou a diferença, debate ensejado em articulações diversas e multifacetadas no meio acadêmico, entre gestores e articuladores de políticas públicas, bem como entre as mais diversas militâncias do campo dos direitos humanos. As repercussões dessas ações remetem a um importante problema político e à própria teoria do conhecimento. Suas metas supõem transformações sociais em grandes dimensões.

Trata-se, pois, de um tema fecundo para reflexão, não só para entender os problemas de gênero, pois está no cerne das polêmicas atuais sobre direitos individuais e identidades de grupo em todos os espaços sociais, culturais, econômicos e políticos.

A seção a seguir contextualizará o cotidiano das prisões da RMF a partir das rebeliões de maio de 2016 que deram visibilidade à atuação das facções no interior das unidades prisionais e que acabaram por provocar a separação dos presos seguindo o critério da filiação aos Comandos. 


\section{Entendendo o contexto prisional do Ceará}

Em Nascimento (2017), a sucessão de crises do sistema penitenciário no Ceará, que culminaram com as rebeliões ocorridas entre 21 e 23 de maio de 2016 na RMF, é contextualizada historicamente. Ressalta-se ali a repercussão da ação das facções nos presídios cearenses durante aquela ocasião: destruição total ou parcial do interior de diversas unidades prisionais e mais de uma dezena de mortes ${ }^{13}$.

Esse evento teve como estopim a greve dos agentes penitenciários que reivindicavam então aumento salarial e melhores condições de trabalho. Para garantir força à luta sindical da categoria profissional, os agentes impediram a visitação de parentes dos internos nas unidades prisionais. A greve durou pouco mais de doze horas, tempo suficiente para instalar o caos dentro e fora dos presídios.

A partir das rebeliões, o Estado iniciou a redistribuição de detentos nos presídios da RMF levando em consideração suas filiações nas facções ${ }^{14}$. Segundo o diretor da CPIS, essa divisão de presos foi a forma preliminar mais efetiva encontrada para tentar conter os constantes embates entre os Comandos no interior dos presídios, evitar a mortandade de presos e os sucessivos ataques a equipamentos públicos que passaram a ocorrer dentro e fora das unidades prisionais após as rebeliões. Dentre esses ataques, ressaltamos a depredação de transportes coletivos e delegacias de Fortaleza ${ }^{15}$. A atuação das facções no interior das unidades prisionais teve reflexos diretos na vida das bichas e dos artigos errados.

A partir do trabalho de campo realizado pelo primeiro autor deste texto entre 2016 e 2018, bem como de vivências anteriores como agente penitenciário atuando em diversas unidades prisionais cearenses, serão apresentadas algumas narrativas sobre as rebeliões e o contexto em que ocorreram. Traremos relatos de pessoas LGBT privadas de liberdade e de profissionais atuantes na CPIS. A observação participante e as entrevistas individuais ou em grupo realizadas com essas pessoas na referida prisão se deram em 2017, passados nove meses do período em que ocorreram as rebeliões. As conversas e o contato direto com pessoas LGBT aprisionados nessa unidade prisional ocorreram em uma sala reservada onde o pesquisador, seus interlocutores e suas interlocutoras ficaram sem a vigilância de agentes penitenciários ou de qualquer outro profissional.

Comecemos com o relato de Érika.

Quando entrevistamos a travesti Érika, de 23 anos, ela cumpria pena em regime fechado na CPIS por assalto. Érika relata que há muito tempo as bichas podiam subir para a cadeia Babilonnia, porém elas tinham que seguir a cartilha das facções: "Numa Babilônia, as bichas têm que estar no lugar delas. As bichastêm que se comportar como homem. Elas não podem mostrar o lado feminino delas de forma alguma" (Érika). A interlocutora complementou seu relato falando da opressão de 
puxar cadeia como homem, ou seja, a impossibilidade de expressar sua feminilidade a partir do uso de batom, roupas e acessórios femininos ou manter relações sexuais com outros presos.

A narrativa de Érika está amparada na comparação entre duas experiências prisionais no sistema penitenciário cearense vividas por ela. Seu cotidiano atual na CPIS, descrito a seguir, é bastante distinto da vida de pessoas LGBT na Babilônia. Lá, relações de poder e hierarquias marcadas pela diferença de gênero e sexualidade a que são submetidas gays, bissexuais e travestis apontam para um padrão dominante masculino e heterossexual imposto aos demais sujeitos não heterossexuais. A submissão a esses padrões visa garantir a continuidade da vida na prisão para esses sujeitos subalternizados.

Pode-se dizer, portanto, que as representações sociais peculiares à heteronormatividade (BUTLER, 2013) são reproduzidas no contexto da prisão, às vezes de forma ainda mais cruel. Alicerçadas em uma ideia de normalidade como verdade autoevidente, essas representações oprimem alguns grupos sociais considerados inadequados, anormais ou incorretos, entre eles, as bichas. A desqualificação dos LGBTs, materializada em ódio, aversão, preconceito, violência e discriminação, é muitas vezes percebida e tratada como fenômeno banal. Tal gramática, acionada por funcionários do Estado, presos e facções, tem como fundamento a superioridade biológica e moral dos comportamentos heterossexuais. No ambiente prisional, essa desqualificação assume características inusitadas.

Sobre essa identidade referência:

\footnotetext{
Se a posição do homem branco heterossexual de classe média urbana foi construída, historicamente, como a posição-de-sujeito ou a identidade referência, segue-se que serão diferentes todas as identidades que não correspondam a esta ou que desta se afastem. A posição normal é, de algum modo, onipresente, sempre presumida, e isso a torna, paradoxalmente, invisível. Não é preciso mencioná-la. Marcadas serão as identidades que dela diferirem (LOURO, 2008, p. 22).
}

No entanto, vale ressaltar que o período descrito por Érika é anterior à influência direta das facções vindas do Sudeste brasileiro ${ }^{16}$ nas gangues locais e à consequente radicalização das gestões dos corpos aprisionados a partir das regras dos comandos.

Sá e Aquino (2018) apontam 2013, período da Copa das Confederações e ano que antecedeu o mundial de futebol, como a data em que as facções passaram a influenciar as gangues locais e a disputar território do mercado das drogas na periferia de Fortaleza. De acordo com alguns interlocutores de nossa pesquisa, nesse mesmo período as facções passaram a interferir diretamente nas políticas de aprisionamento e, consequentemente, na vida dos detentos. Tornaram-se, portanto, agentes que jamais podem ser desconsideradas no interior das unidades prisionais. 
A partir de 2016, as regras das facções, fortemente marcadas por relações de gênero; sexualidade e classe, exigiram do Estado a separação imediata dos presos em unidades específicas, de acordo com suas filiações. Ao acatar a reivindicação, a administração prisional tinha como intuito a contenção dos constantes embates entre facções rivais. Paralelo a isso, as bichas e os artigos errados, grupos frequentemente discriminados e violentados no cotidiano da prisão, foram expurgados da Babilônia e transferidos para unidades prisionais específicas sob o discurso institucional da preservação de vidas tidas como frágeis e vulneráveis. Vale destacar ainda que, já há algum tempo, esses grupos não dividiam as mesmas alas ou celas que as facções, mas espaços reservados nas mesmas unidades prisionais. O encontro desses grupos era pouco provável, a não ser durante as rebeliões.

Os atos envolvidos nas rebeliões de 2016 em Fortaleza, sua repercussão na mídia local e nacional e os custos públicos e o planejamento técnico demandados para a minimização de suas repercussões evidenciam a expansão dos grupos criminosos organizados nos presídios cearenses.

Seguindo uma linha de análise ainda pouco explorada nos estudos sobre prisão, Lago e Zamboni (2016) propõem lançar um olhar sobre como múltiplas formas de diferença e desigualdade se articulam e são produzidas no âmbito prisional. Argumentam que, embora a articulação entre raça e classe esteja presente na maioria dos estudos sobre prisões no Brasil, pouco se articula gênero e sexualidade no mesmo contexto. Nessa tendência, ignora-se a relação entre masculinidade e criminalidade "ou sobre o fato de que as prisões são fundamentalmente lugares 'para homens heterossexuais"' (LAGO e ZAMBONI, 2016, p. 05).

Falando do contexto paulista, Dias (2011) relata que as relações de poder entre presos passaram por sucessivas mudanças após a consolidação do PCC. Em se tratando dos "presos homossexuais" (DIAS, 2011, p. 207), a autora aponta dois eventos que vão ressignificar suas presenças nas prisões dominadas pelo Comando. O primeiro diz respeito ao artigo oito do código de conduta do PCC (Ibid.), que proíbe estupros e violências sexuais entre presos. Tal regra tinha o objetivo de impedir que os malandrões ${ }^{17}$ fizessem os outros presos de mulherzinha ${ }^{18}$ na prisão. O segundo evento se refere à proibição das relações homossexuais dentro das unidades prisionais. "Essas proibições vieram acompanhadas do alargamento da discriminação e da segregação de comportamentos homossexuais" (Ibid., p. 207). Proibições baseadas na suposição da normalidade e superioridade da condição heterossexual.

As reações do PCC e demais facções a marcadores de identidade de gênero e orientação sexual parecem estar amparadas na legitimação de crenças sobre o que seria verdadeiro, correto ou natural. Reações, portanto, marcadas por um fundo religioso, moral ou ideológico. Aqui convém lembrar Salih (2013, p. 13), ao interpretar o pensamento de Butler no tocante à dialética como um processo aberto, e a assertiva desta de que toda resolução se apresenta como perigosamente antidemocrática. Na ótica de Butler (2013), ideias e teorias que se apresentam 
como verdades autoevidentes são frequentemente presas fáceis para pressupostos ideológicos que aprisionam minorias e grupos marginalizados. Salih (2013) cita como exemplo as noções conservadoras que consideram a homossexualidade como imprópria, contra a natureza, anormal, enfim, algo a ser punido e proibido.

Nessa mesma linha de raciocínio, Dias (2011) fala que a repulsa dos presos faccionados por homossexuais obedece a uma categorização moral que os classifica como sujos, portadores de inferioridades sociais e menos humanos.

Ao relatar sua experiência na Babilônia, Érika denomina os presos faccionados de machistas e denuncia a tirania por não poder expressar sua identidade de gênero ou sua orientação sexual no interior da prisão.

Tal categorização moral, vivenciada de forma dramática por Érika, encontra-se muito bem construída e materializada nos discursos e colóquios cotidianos, não sendo particular ao discurso eliciado pelas facções em ação no Ceará.

Para Butler (2013), linguagem e discurso constroem gênero. Não existe uma identidade de gênero que preceda a linguagem. Ou seja, as normas de gênero são constituídas e mediadas linguisticamente. Como nem o estilo nem a gramática são politicamente neutros, é visível que a repulsa dos presos faccionados pelos homossexuais esteja contaminada pela moral conservadora que considera a homossexualidade como imprópria, avessa à natureza, anormal e como algo a ser refutado, proibido e punido. Trata-se de atitudes que pretendem ser naturalmente corretas em algum sentido, seja religioso, moral ou ideológico, fortemente referenciadas nos discursos cotidianos da sociedade heterocêntrica.

Após as rebeliões, a separação dos presos garantiu a cada facção uma unidade prisional exclusiva. Já internos e internas LGBT, bem como os artigos errados, foram transferidos para a CPIS. De acordo com Amora, travesti presa por assalto, as bichas foram encaminhadas juntamente com os duzentos para a CPIS que ainda estava em construção.

- Nós não tínhamos onde ficar. Os presos faccionados não aceitaram mais que ficássemos na mesma cadeia que eles, então viemos pra cá. Metade fugiu e o restante ficou. Aqui não tinha grade, não tinha nada. (Amora)

Em sua etnografia realizada no sistema prisional de São Paulo, Marques (2009) reflete sobre o proceder no mundo do crime, permitindo-nos perceber que valores morais giram em torno da gestão da sexualidade na prisão. De acordo com o autor, presos com proceder seriam aqueles respeitados e passíveis de interação com os demais na prisão. Já os desprovidos de proceder seriam os presos moralmente discriminados, perseguidos e segregados do convívio. No contexto cearense, a distinção entre presos com ou sem proceder seria análoga à condição dos presos 
faccionados e dos artigos errados e/ou equiparados, como os LGBTs. São noções, ideias e conceitos impregnados por valores morais e religiosos acionados cotidianamente e propagados, principalmente pelas instituições do Estado, família, escola, igreja e pela mídia.

$\mathrm{Na}$ CPIS ainda em fase de construção, pessoas LGBT passaram a dividir o espaço com os artigos errados. Tal deslocamento modificará as formas de expressão de identidade de gênero e orientação sexual naquela unidade. A partir de meados de 2016, longe do discurso machista das facções, Érika fala sobre como é dividir cadeia com os artigos errados.

\footnotetext{
- A gente se sente melhor estando no meio dos artigos errados. Porque eu já puxei Babilônia e sei como é que é. Aqui a gente se solta! A gente veste roupa de mulher, aqui a gente usa cocozinho ${ }^{19}$, aqui a gente põe batom se a gente quiser... Mas na Babilônia, não! Na Babilônia a gente tem que se comportar como homem, a gente é um homem! Aqui, a gente tem a liberdade total de se expressar como a gente é. Aqui ninguém pode discriminar o outro porque no entender das facções todos somos errados. (Érika)
}

Para a interlocutora, sua expulsão do convívio dos presos faccionados permite-lhe vivenciar sua identidade de gênero e orientação sexual, já que tanto presos e presas LGBT quanto os artigos errados foram considerados inadequados para o convívio com os membros das facções.

Ainda que longe das facções e seu machismo, os marcadores de gênero e sexualidade expressos por Érika estão submetidos a modulações de outro agente: o Estado. Utilizando o discurso de que se trata de uma unidade prisional destinada a homens, a administração da CPIS impede a entrada de roupas femininas, batom, maquiagem ou outros adereços que compõem usualmente a inscrição do feminino nos corpos das travestis. Tampouco é permitida a manutenção do tratamento hormonal, a visita de companheiros e a utilização do nome social pela via institucional. Se observarmos as políticas públicas voltadas para pessoas marcadas por gênero e sexualidade, como é o caso dos LGBTs em cumprimento de pena privativa de liberdade, podemos perceber o padrão heterossexual como "dominante nos sistemas punitivos de forma mais ampla" (LAGO e ZAMBONI, 2016, p. 10).

A propósito das políticas públicas no âmbito prisional, não obstante a Constituição brasileira se proponha a promover o bem de todos, sem preconceitos de origem, raça, sexo, cor, idade e quaisquer outras formas de discriminação, lamentavelmente ainda estamos muito longe de sermos uma sociedade sem preconceitos. Os casos diários de agressões físicas e homicídios em todo o território nacional, nos espaços públicos, nas escolas, nas famílias, no mercado de trabalho, nas igrejas e na mídia, são apenas algumas ocorrências cotidianas de privação de direitos que continuam a vitimizar a população LGBT. Como descrito ao longo do artigo, o contexto dos presídios cearenses após as rebeliões de 2016 parece evidenciar um jogo imbricado de relações entre Estado, facções e sujeitos aprisionados que vulnerabilizam pessoas LGBT de forma 
específica considerando seus marcadores de gênero, origem e localização social. Não raro, essa sobreposição de situações de precariedade implica em violência fatal contra esses sujeitos.

Diante da negativa institucional, para recomporem suas identidades as travestis recorrem a barganhas de roupas e acessórios com as visitantes, no intuito de manter as características femininas performatizadas (BUTLER, 2013) em seus corpos. "As visitas vendem pra nós as peças de roupas. Às vezes, a visita do cara deixa um short ou uma blusa na cela e a gente negocia" (Fernanda). Durante o trabalho de campo, uma das agentes penitenciárias confidenciou que frequentemente presenteia as internas com batons e esmaltes, ainda que a prática destoe das regras institucionais da unidade. "Eu gosto das viadas [travestis], são presos que não dão trabalho" (Agente penitenciária). Durante uma roda de conversa realizada ao longo da pesquisa ${ }^{20}$, as internas confirmaram o relato da servidora e ainda complementaram: "A gente pede e ela dá. A Dona Agente é a mais boazinha!" (Amora) ${ }^{21}$.

Érika, a quem já nos referimos anteriormente, esboça sua angústia em não poder prosseguir o tratamento hormonal na penitenciária. Compara as regras da CPIS com as de outra unidade prisional cearense, onde haveria um tratamento mais humanizado às travestis. - Aqui não pode, mas lá no Irmã Imelda pode, né? Lá é totalmente diferente! Lá, as bichas se sentem
melhor, porque eu me sinto um lixo sem tomar meus hormônios! Eu não me sinto bem da cabeça sem
eles... Ai... Eu fico sufocada, não me sinto bem. (Érika)

A interlocutora continua sua fala referindo-se aos prejuízos ocasionados em seu corpo pela interrupção do tratamento hormonal. Destaca que sua pele já não é mais macia como antes, que os pelos crescem rapidamente e que os seios diminuem ${ }^{22}$. É visível que tais efeitos influenciam negativamente a autoestima das travestis presas na CPIS.

Com o fim da construção e a consequente inauguração da CPIS, a unidade foi destinada para a massa carcerária, sendo dois pavilhões designados aos presos expurgados da convivência na Babilônia e/ou com pouca ou nenhuma convivência junto aos presos não faccionados - os espirrados. Os presos e as presas LGBT e os Jacks ocupam os mesmos pavilhões no estabelecimento prisional.

Percebe-se, portanto, uma pulverização de políticas públicas de aprisionamento no estado, o que implica distintas experiências institucionais pelos presos LGBT.

A partir de 2016, pode-se dizer que a ação de diferentes facções no Ceará é parte determinante das ações de planejamento de ocupação de equipamentos públicos de forma heterogênea, garantindo direitos a determinados presos e não a outros. Ao mesmo tempo, a existência de uma experiência institucional em que presos LGBT acreditam ter suas identidades respeitadas permite ao Governo do Estado do Ceará a divulgação em jornais veiculados e vídeos institucionais de uma política de inclusão de alcance bastante limitado como se esta atendesse a toda a população LGBT 
nos presídios cearenses. Se pensarmos política institucional como políticas planejadas pelo Estado de forma a definir direitos e deveres equânimes entre cidadãos, poderíamos dizer que inexiste uma política coerente para a população prisional LGBT no estado do Ceará.

Durante o período da pesquisa aqui relatada, pudemos perceber como a situação de inequidade de direitos implica na negociação de trânsitos entre instituições dos presos LGBT. Narrativas sobre a preferência das travestis de se relacionarem com os Jacks na CPIS ou de utilizarem adereços femininos na unidade prisional Irmã Imelda permitem-nos construir uma narrativa de trânsitos e anseios dessa população usualmente invisibilizada. Ao mesmo tempo, formas de disciplinarização dos corpos LGBT são acionadas por diferentes agentes, exigindo comportamentos ideais que correspondam ao desejo do Estado e das facções. Tal situação torna a vida das pessoas LGBT ainda mais precária e incerta, colocando-as em estado de negociação contínua com mediadores institucionais e não institucionais a fim de preservar valores considerados fundamentais para esses presos e presas LGBT, entre eles, o direito à identidade e à memória social.

\section{Relações e relacionamentos de LGBTs entre o dentro e fora da prisão}

A precariedade do aprisionamento no Brasil não é um fenômeno recente na nossa história, embora tenha se agravado com o inchaço das prisões e a morosidade dos órgãos estatais diretamente vinculados ao sistema penitenciário brasileiro. Em um Estado que nunca consolidou o bem-estar e a proteção social, a prisão se consolidou como uma forma de punição por excelência, uma vez que mesmo as necessidades básicas de quem é aprisionado jamais são inteiramente atendidas (WACQUANT, 2001; LOURENÇO, 2015; GODOI, 2015).

A insuficiência na garantia de condições básicas à sobrevivência no cárcere imputa ao Estado gerenciar o trânsito de pessoas, objetos e informações que entram e saem das unidades prisionais. Além de garantirem o funcionamento das prisões, esses trânsitos entre o dentro e fora caracterizam as porosidades que alicerçam as inúmeras articulações do prisional com o urbano (GODOI, 2015). No Ceará, há uma intricada rotina que marca os fluxos de familiares, advogados, amigos, profissionais e religiosos no interior dos presídios (NASCIMENTO, 2018a, 2018d, 2018e). Nos dias de visita, familiares e amigos têm sua entrada permitida nas unidades prisionais, usualmente portando malotes $^{23}$ entre outros inúmeros itens permitidos pela administração prisional. Tais objetos materializam a diversidade de formas de relação e vivências complexas no interior dos presídios brasileiros.

As porosidades que articulam o dentro e o fora das prisões foram sistematizadas por Rafael Godoi (2015) nos conceitos de vasos comunicantes e fluxos penitenciários. Entende-se por vasos 
comunicantes toda forma, meio ou ocasião de contato entre o dentro e fora da prisão, que em uma dimensão particular articula a comunicação entre os dois mundos e envolve bloqueios. Neles, "múltiplas negociações, determinações, poderes e disputas operam na diferenciação do que entra e sai, dificultando ou facilitando acessos, registrando (ou não) as passagens e estabelecendo destinações" (GODOI, 2015, p. 136).

As visitas de familiares, amigos, advogados particulares e religiosos; os profissionais com diversas funções no interior das prisões; os meios de comunicação permitidos e não permitidos - aparelhos de rádio, televisão, celulares ${ }^{24}$ e catatais $^{25}$; a entrada e saída de presos nos regimes de pena; e os malotes são alguns dos exemplos de vasos comunicantes que permeiam as prisões cearenses nos meandros do formal e do informal, do lícito e do ilícito.

Ainda de acordo com o autor, os fluxos penitenciários se constituem a partir dos múltiplos vasos comunicantes: o fluxo da população carcerária, o fluxo de agentes estatais, o fluxo de familiares e amigos de presos, o fluxo das coisas e das informações. A prisão é, portanto, entendida "como um local de circulação ampliada, mais que de segregação e confinamento; como um território recortado, mas amplamente articulado com outras territorialidades" (Ibid., pp. 140-141).

Se considerarmos as prisões a partir de porosidades operacionalizadas a partir da circulação de pessoas, informações e objetos, teremos que pensar que relações e relacionamentos de LGBTs presentes no cotidiano da prisão excedem o interior das celas. Por meio da circulação de objetos, sempre atravessada por marcadores sociais da diferença, é possível perceber práticas sexuais criativas que informam as performances de gênero, as relações de poder e a hierarquia que constituem o mundo, dentro e fora da prisão, a partir de suas estrias (DELEUZE, 1997). Nossa argumentação está assentada nas informações e discussões que vêm sendo pontuadas desde o início deste artigo, tendo em vista as particularidades da unidade prisional que tomamos como lócus. Assim, tomaremos a seguir os relatos de presos e presas LGBT como fonte e parâmetro para uma reflexão.

Michel está preso há sete meses acusado de uma dezena de crimes. Ele se considera gay e mantém um relacionamento com outro rapaz há pouco mais de um ano e sete meses. O interno diz que sente muita falta dos momentos íntimos com o namorado, embora ele o visite uma vez por mês na CPIS no dia da visita de pais e familiares masculinos ${ }^{26}$. Michel expõe sua indignação por não poder receber seu namorado para o momento íntimo na cela, uma vez que a unidade não permite a visitação de companheiros de homossexuais. Tampouco os outros presos com quem divide a cela aceitam o contato sexual entre Michel e seu companheiro. O momento de aproximação entre eles se dá com seus corpos separados pela grade e sob a vigilância dos demais internos. São situações que retratam formas desumanas dos sujeitos se relacionarem com seus corpos, de buscarem seus desejos e de criarem situações que lhes possam ser prazerosas como direito em uma sociedade que ainda não acredita que uma das liberdades fundamentais seja a liberdade de gênero e sexualidade. 
Para satisfazer-se e satisfazer sexualmente seu companheiro no período de aprisionamento, Michel abriu mão da monogamia e agracia seu namorado com garotos de programa sempre que percebe a carência dele. "Eu acesso os sites e escolho o boyzinho no estilo que ele gosta - novinho, bonito, alto e musculoso, e pago na condição de que ele grave ou compartilhe a relação sexual em tempo real via aplicativo de celular" (Michel). O interlocutor afirma que essa foi uma das estratégias que encontrou para manter seu relacionamento diante da impossibilidade do contato sexual na prisão. As estratégias utilizadas para a vivência dos desejos no interior das prisões, em visíveis condições adversas, fazem lembrar novamente Butler (2013) quando a autora afirma ser o gênero limitado pelas estruturas de poder no interior das quais os corpos estão situados, não obstante a possibilidade de proliferação e subversão que se abrem a partir dessas limitações.

Como percebido por Padovani (2011), embora proibido no interior das unidades prisionais, o aparelho celular tem grande circulação e é corriqueiramente utilizado por internos para se comunicar com o mundão ${ }^{27}$, inclusive pelas facções que atuam dentro e fora das prisões.

Michel vive um relacionamento marcado pelo impedimento de contato corporal e marcado pela diferença conformada por noções de gênero, sexualidade e classe social. Nesse relacionamento, o uso criativo do celular permite e orienta a dinâmica dos desejos que possibilita borramento e apagamento de fronteiras entre o casal. É a partir do uso desse vaso comunicante que Michel mantém contato diário com seu companheiro: escolhe, contrata e paga o profissional do sexo para satisfazê-lo. Em contrapartida, o interno é beneficiado com a possibilidade de manter relações sexuais com outros internos no interior da cela. Ele afirma que as relações sexuais empreendidas, tanto por seu namorado como por ele, não devem conter trocas de afetos, carinho e carícias, uma vez que esses atributos são específicos do compromisso deles na relação conjugal. São códigos de conduta cujos limites estabelecem fronteiras na vivência de uma sexualidade possível para os que não se enquadram nas normas de gênero e nas expectativas da heterossexualidade.

Enquanto ouvíamos o relato de Michel na roda de conversa, Érika aguardava ansiosa para dar seu depoimento. Para ela, a forma como seu colega de cela levava seu relacionamento era totalmente arbitrária, seu namorado jamais aceitaria situação semelhante. Também mantendo contato com seu companheiro via celular, Érika jura fidelidade a ele. No entanto, confidenciou que estar na mesma vivência que os Jacks faz dela uma mulher constantemente desejada e, com isso, explora no interior da cela relações sexuais com diferentes parceiros, tomando cuidado para não se envolver sentimentalmente.

Relata ter preferência pelos homens casados, visto que estes dificilmente se envolveriam em relacionamentos duráveis com pessoas LGBT na prisão. As esposas dos presos casados os visitam semanalmente no sábado ou domingo. Além da permissão para estabelecer visitas íntimas entre 
casais heterossexuais, o trânsito das esposas e dos malotes que as acompanham são fundamentais para o atendimento de necessidades básicas na prisão.

Amora fala do respeito que os artigos errados têm com as travestis e das relações que se estabelecem no interior das celas na CPIS. "Aqui, no meio deles, a gente é tratada como princesa! Aqui, a gente se sente mulher!" (Amora). "É aquele ditado: em terra de cego quem tem um olho é rei. Então, aqui..." (Fernanda).

— Vamos supor... A visita é dia de domingo, ele tem a visita dele, mas é só naquele domingo, e a semana todinha é a gente. Entendeu? Nós estamos aqui todos os dias! Nós estamos morando juntos, nós estamos compartilhando as mesmas coisas, estamos dormindo no mesmo espaço, comendo da mesma comida. Entendeu? Ai é tudo! Para meu namorado eu digo que sou uma santa! (Érika)

Embora as travestis frisem a deferência que os artigos errados têm com elas, principalmente no que se refere à expressão dos aspectos femininos empreendidos em seus corpos, vale destacar que, mesmo que houvesse a anuência da direção da CPIS para a entrada dos companheiros das bichas para o momento íntimo na cela, a visitação seria impossibilitada tendo em vista as regras cultivadas entre a maioria dos presos, que não são LGBT, em proibir a entrada de visitantes homens companheiros das bichas nas celas.

Assim, os mesmos presos que mantêm relações sexuais com as bichas quando conveniente, e que não se identificam como homossexuais, repudiam o contato íntimo entre seus companheiros LGBT de cela e visitantes, mesmo em situações em que esse contato obedeça às normas estipuladas pela administração prisional ${ }^{28}$. Esse caleidoscópio de regras compõe a conduta dos presos no cotidiano da prisão. Aqui, marcadores de gênero e sexualidade são remetidos à própria noção de diferença que, segundo Michel, remete ao preconceito da sociedade que insiste em condenar as relações homossexuais. Que insiste em desqualificar, assediar, agredir e assassinar pessoas que não se enquadram nas normas de gênero, que não se submetem à heteronormatividade.

\section{Considerações finais}

O sistema prisional do Ceará passou por inúmeras transformações a partir dos tensionamentos entre facções e Estado, que repercutiram nos âmbitos estadual e nacional por meio das rebeliões de 2016. Tais mudanças demandaram complexas dinâmicas que envolvem a gestão de presos faccionados, massa carcerária, pessoas LGBT e artigos errados, mas também a gestão do fluxo de visitantes, objetos e informações que permeiam os processos de Estado que regulam o acesso entre o dentro e o fora das prisões. Trata-se de todo um aparato de Estado que 
gesta sobre a vida de diferentes grupos em situação de privação de liberdade. Todos esses grupos foram atingidos pelos conflitos entre facções e Estado, assim como pelos expedientes utilizados na tentativa de minimizar a repercussão desses conflitos.

O lugar de destaque alçado pelas facções no Ceará impôs ainda a adequação das pessoas LGBT a novas formas de opressão impostas pelos Comandos. Fortemente informadas pelas marcações gênero e sexualidade, os códigos de determinadas facções para o convívio com pessoas LGBT nas prisões regulam desde formas cotidianas de se vestir e como se portar até a repulsa total das bichas do convívio na Babilônia, sob a justificativa não apenas de que "o crime não dá o cu" (BIONDI, 2010, p. 148), mas de que o crime também não se mistura com quem dá o cu.

Como descrito ao longo do artigo, os conflitos ocorridos em 2016 no Ceará ocasionaram a expulsão de pessoas LGBT e dos artigos errados da Babilônia. Na memória de nossos interlocutores e interlocutoras, foi possível a partir de então expressar os aspectos femininos empreendidos em seus corpos e desenvolver com os Jacks relações de cunho afetivo-sexuais. Profundamente marcadas pela situação precária vivida na prisão, pela opressão de suas identidades sexuais pelo Estado e pelas facções, bem como pela gramática heteronormativa comum em nossa sociedade, tais relações não alcançam o status de parcerias duradouras.

Por outro lado, impedidos de receberem visitas íntimas de seus namorados e maridos, as pessoas LGBT em cumprimento de pena na CPIS utilizam o celular e a criatividade como meios de contato com seus companheiros da liberdade. $\mathrm{O}$ artefato, proibido no interior da prisão, é vastamente explorado em estratégias de satisfazer-se e satisfazer sexualmente seus companheiros, seja por trocas de imagens e vídeos, seja escolhendo e pagando profissionais do sexo no intuito de garantir a continuidade das variadas formas de relação estabelecidas entre o dentro e o fora da prisão.

Aparentemente, as relações e os relacionamentos produzem e são produzidos diante das contingências da prisão, seja pelo conjunto de regras formais impostas pela administração prisional e/ou pelas regras impostas ou negociadas entre presos que marcam o lugar e seus sistemas de produção de diferenças. Dessa forma, os marcadores de diferenciação subjetivados nos estilos corporais e nas formas de vivenciarem suas sexualidades impõem às bichas relações de poder e hierarquia no cotidiano da prisão. Nessa linha de análise, não se pode pensar políticas de encarceramento sem pensar um campo de relações estabelecidas entre os múltiplos atores que se fazem presentes na prisão, quais sejam: a administração prisional, agentes penitenciários, as visitantes, as facções, os artigos errados, a massa carcerária e as pessoas LGBT.

A precarização multifacetada da sexualidade vivida na prisão e o fato de o corpo ser um artefato excessivamente pregnante às ideias de subjetividade e verdade sobre o eu fazem com que múltiplas formas de resistência encontrem nos corpos seus condutos de expressão. São narrativas sobre a 
necessidade de manter o cabelo grande e a pele macia, reivindicações pela possibilidade de "dar pinta", pretensões de uma vida íntima como espaço cognitivo (RAPPORT, 2000; MARQUES, 2016) de refúgio.

Como pretendemos desenvolver ao longo do artigo, a confluência de opressões vividas por pessoas LGBT por companheiros de prisão, facções e regras do Estado possui temporalidades e espacialidades múltiplas. Ela é certamente anterior às rebeliões de 2016, mas se radicaliza com a força dos comandos nas prisões cearenses, podendo levar a violência fatal contra presos e presas LGBT. Espacialmente, a opressão se ordena de forma díspar, de acordo com a instituição onde o preso se encontra: se na Babilônia eles e elas poderiam ser exterminados por regras das facções, na CPIS ou no Irmã Imelda ${ }^{29}$ podem se expressar, ainda que exilados em alas específicas.

Nesse universo simbólico específico, o uso de celulares, atributos físicos e jogos sexuais afetivos parecem ocupar um lugar estratégico. São pontos de fuga de vidas "sufocadas" (FOUCAULT, 2000) pela moral das facções, pela moral do Estado, pela moral dos companheiros de cela, pela moral heterossexual e monogâmica.

A distinção com que essas estratégias são assinaladas, quando se deseja ouvi-las, não deixa dúvidas quanto a sua importância na sobrevivência psíquica de nossas interlocutoras e interlocutores. No entanto, o lugar abjeto das relações de gênero e sexualidade nas demandas por direitos humanos tantas vezes cala os lugares de resistência articulados pelos sujeitos, reforçando mais uma vez a lógica heterossexual e monogâmica.

Tais reflexões nos remetem ao lugar do gênero e da sexualidade na reflexão sobre o Estado, suas diferentes políticas e formas institucionais. Convidam-nos ainda a perceber relações perigosas entre Estado, facções e o discurso sobre direitos humanos. À medida que novos interlocutores e interlocutoras são convidados a falar sobre como tecem sua humanidade às relações que hierarquizam pessoas a partir de seus marcadores sociais, radicaliza-se o desafio de constituir um cenário concretamente democrático capaz de reconhecer e acolher as pessoas para além dos discursos que as controlam, como sugere Butler (2013).

\section{Notas}

' Sá e Aquino (2018) apresentam evidências da presença do CV e do PCC nas periferias de Fortaleza ainda no final da
década de 1990 e início dos anos 2000 . No entanto, os autores afirmam que a atuação dos coletivos criminais no Ceará
(CV, PCC, FDN e GDE) só ganhou destaque na segunda década de 2000, em torno das disputas por território e mercado
das drogas dentro e fora das prisões. Os autores apontam que Fortaleza tornou-se uma importante rota de distribuição
de drogas para outros estados do Brasil e para os países do Atlântico. Isso se deu justamente pela intensificação do
policiamento e da vigilância na fronteira do Brasil com o Paraguai e a Argentina. A história da criação do CV e do PCC é
exaustivamente discutida na literatura sobre prisões, no entanto, ainda são escassos estudos que abordem a formação da
FDN e GDE. Sobre a criação das facções do Amazonas e Ceará, ver Siqueira e Paiva (2017) e Sá e Aquino (2018).
${ }^{2}$ Conforme sinalizamos desde o início deste texto, as análises deste artigo referem-se exclusivamente à penitenciária CPIS.
O presídio Irmã Imelda, que ganhou notoriedade como uma das primeiras unidades prisionais voltadas a pessoas LGBT 
no Brasil, só será tematizado a partir do cotejamento frequente nas falas de pessoas LGBT ao comparar as distintas experiências de prisão nas duas unidades.

${ }^{3}$ Diante da recusa dos presos faccionados em permanecer nos mesmos presídios que pessoas LGBT e a consequente destruição dos estabelecimentos prisionais motivados por essa recusa, a Secretaria de Justiça e Cidadania transferiu os presos rejeitados do convívio dos demais para as unidades CPIS e Professor José Sobreira Amorim, ambas ainda em construção no momento da transferência.

${ }^{4}$ Neste texto adotamos o itálico para expressões êmicas colhidas em meio ao trabalho de campo. Os interlocutores e as interlocutoras são caracterizados por nomes fictícios, com o objetivo de preservar suas identidades.

${ }^{5}$ Presos e presas LGBT, embora não respondam por nenhum desses crimes, têm a carga de estigma equiparada aos artigos errados.

${ }^{6}$ Bichas é a forma como presos e presas gays, bissexuais, travestis e transexuais aglomeram em um só termo todas as pessoas que mantêm relações sexuais ou afetivas com pessoas do mesmo sexo. $O$ termo assinala ainda sujeitos com corpos masculinos que mantêm características, posturas e gestos considerados femininos.

${ }^{7}$ Termo usado para designar os pavilhões e as unidades prisionais dominados por facções.

${ }^{8}$ Duzentos ou Jacks é como são chamados os presos que cometeram crimes sexuais prescritos no art. 213 do Código Penal Brasileiro. "Constranger alguém, mediante violência ou grave ameaça, a ter conjunção carnal ou a praticar ou permitir que com ele se pratique outro ato libidinoso" (BRASIL, 2017, p. 85). Na lógica do crime, duzentos ou Jacks cometeram crimes errados, recebendo a alcunha de artigos errados.

${ }^{9}$ Companheiros não presos.

${ }^{10}$ Agradecemos a possibilidade de discutir a versão preliminar deste texto no Simpósio Temático n 41 - "Diversidade Sexual e de Gênero na Prisão: Entre a Universidade, o Ativismo e as Políticas Públicas" do $3^{\circ}$ Seminário Internacional Desfazendo Gênero, ocorrido em Campina Grande, Paraíba. Agradecemos também aos pareceristas anônimos deste periódico pelas contribuições para o aprimoramento da versão aqui apresentada. A pesquisa contou com financiamento da Fundação Cearense de Apoio ao Desenvolvimento Científico e Tecnológico (Funcap).

${ }^{11}$ Marcadores sociais de diferença são categorias que funcionam como ferramenta analítica para apreender as articulações das múltiplas diferenças e desigualdades (raça, classe, gênero, sexualidade). Em contextos específicos, essa ferramenta analítica possibilita a observação de interações e coprodução entre diferentes marcadores (PISCITELLI, 2008).

${ }^{12}$ É importante lembrar que as posições binárias se pretendem explicativas não tanto das práticas, consideradas infinitas e matizadas entre si mesmas, mas da variedade de sistemas de classificações.

${ }^{13} \mathrm{O}$ número total de mortos é controverso, uma vez que os corpos foram mutilados e carbonizados, dificultando assim a identificação e contagem. Nesse mesmo período, houve inúmeras fugas em massa das unidades prisionais que dificultaram a recontagem dos presos que morreram, fugiram ou permaneceram nos presídios. De acordo com o relatório do Ministério Público (NASCIMENTO e FREITAS, 2019), o número oficial de mortos nas rebeliões é de 14 presos.

${ }^{14}$ Apesar das realocações de presos nas unidades prisionais serem constantes, no momento da escrita deste texto as facções estavam alocadas da seguinte forma: CPPL III - PCC, CPPL 4 e IPPO II - GDE. Os demais presídios da RMF estão destinados aos presos filiados ao CV e à FDN que permaneceram aliados. Sobre um levantamento das instituições prisionais cearenses, ver Nascimento (2017, 2018a).

${ }^{15}$ Os ataques às delegacias e aos ônibus ganharam destaque na imprensa local e nacional. Para outras informações a respeito, ver Nascimento $(2017,2018$ a) e Bezerra (2018).

${ }^{16}$ O PCC e o CV são dois dos principais Comandos que impuseram novas normas no interior das prisões (NASCIMENTO, 2018a).

${ }^{17}$ Presos fortes, viris como atributos de masculinidade e que detém poder organizacional no interior da cela.

${ }^{18}$ Presos subjugados a assumir a posição sexual passiva nas relações sexuais entre homens presos, posição atribuída ao feminino.

${ }^{19}$ Forma de amarrar os cabelos, geralmente utilizando uma liga elástica ou presilha.

${ }^{20} \mathrm{Na}$ roda de conversa, estávamos Elionardo, Michel, Érika, Fernanda e Amora.

${ }^{21}$ Marques, Feitosa e Palmeira (2014) discutem a ação de trabalhadores vinculados a instituições públicas na relação com usuários e usuárias dessas instituições. Os autores propõem que tal ação seja percebida por meio de análises interseccionais, que levem em consideração origem social, geração, raça e outras marcações postas em ato no contato com o público ali atendido.

${ }^{22}$ Os efeitos do tratamento hormonal no corpo das travestis foram relatados nas etnografias de Don Kulick (2008), Larissa Pelúcio (2009), Marcos Benedetti (2005) e Nascimento (2018a, 2018b, 2018c).

${ }^{23}$ Sacolas enormes contendo alimentos, roupas, cigarro, materiais de higiene, colchões, lençóis e medicamentos. 
${ }^{24} \mathrm{O}$ uso, o porte ou a posse de aparelhos celulares no interior das unidades prisionais é vedado pela Lei de Execução Penal (BRASIL, 1984).

${ }^{25}$ Catatais são bilhetes escritos pelos internos com finalidade específica. Eles podem transitar tanto no interior da unidade como fora dela.

${ }^{26} \mathrm{Na}$ ausência de um familiar, é permitida a entrada de um amigo como visitante. Nesse caso, como o interno é natural de outro estado e não recebe visita de familiares, foi permitida a visitação do seu companheiro na condição de única visita.

${ }^{27}$ Faz referência aos espaços fora das unidades prisionais.

${ }^{28} \mathrm{O}$ contato afetivo-sexual entre presos e presas LGBT com seus companheiros não privados de liberdade seria possível em uma rara configuração: uma vez por mês, é possível que familiares homens visitem seus presos. Na inexistência de cadastro de familiares, homens que não possuem vínculo familiar poderiam realizar essas visitas. Trata-se, portanto, de uma situação incomum. Ainda que excepcionalmente, alguns presos e presas LGBT poderiam se beneficiar dessa política. A situação é impossibilitada pelo repúdio dos companheiros de cela de LGBTs aprisionados que não permitem a entrada de visitantes homens, familiares ou não, no interior da cela.

${ }^{29}$ Uma seleção realizada em unidade específica para a classificação de presos como perigosos, menos perigosos e vulneráveis por profissionais da segurança prisional e da assistência psicossocial determina que presos ficam em cada um desses dois presídios. Presos e presas não considerados perigosos são encaminhados ao Irmã Imelda. $O$ trânsito entre presídios constrói narrativas sobre vantagens e desvantagens de se encontrarem alocados e alocadas em cada um desses aparatos do Estado, tema que foi desenvolvido em artigo específico (NASCIMENTO, 2020). 


\section{Referências}

BENEDETTI, Marcos Renato. Toda feita: O corpo e o gênero das travestis. Rio de Janeiro: Garamond, 2005.

BEZERRA, Sergiana de Sousa. Trabalho e saúde de agentes penitenciários no Instituto Psiquiátrico Governador Stênio Gomes. 2018. Dissertação (Mestrado em Sociologia) Universidade Estadual do Ceará, Fortaleza, 2018.

BIONDI, Karina. Junto e misturado: Uma etnografia do PCC. São Paulo: Terceiro Nome, 2010.

BRASIL. Código penal (1940). Brasília: Senado Federal, Coordenação de Edições Técnicas, 2017.

BRASIL. Lei no 7.210, de 11 de julho de 1984. Institui a Lei de Execução Penal. Disponível em: http://www.planalto.gov.br/ccivil_03/LEIS/L7210.htm

BUTLER, Judith. Problemas de gênero: Feminismo e subversão da identidade. Rio de Janeiro: Civilização Brasileira, 2013.

DELEUZE, Gilles. “Tratado de nomadologia: A máquina de guerra”. In: DELEUZE, Gilles; GUATTARI, Félix. Mil platôs: Capitalismo e esquizofrenia. Rio de Janeiro: Editora 34, 1997, pp. 11-110.

DIAS, Camila Nunes. Da pulverização ao monopólio da violência: Expansão e consolidação do Primeiro Comando da Capital (PCC) no sistema carcerário paulista. Tese (Doutorado em Sociologia) - Universidade de São Paulo, São Paulo, 2011.

FOUCAULT, Michel. “A vida dos homens infames”. In. O que é um autor? Lisboa: Passagens, 2000, pp. 89- 126.

FRY, Peter. "Da hierarquia à igualdade: A construção histórica da homossexualidade no Brasil". In: Para inglês ver: Identidade e política na cultura brasileira. Rio de Janeiro: Zahar, 1982, pp. 87-115.

GODOI, Rafael. "Vasos comunicantes, fluxos penitenciários: Entre o dentro e o fora das prisões de São Paulo". Vivência: Revista de Antropologia, vol. 1, n. 46, pp. 131-142, 2015.

KULICK, Don. Travesti: Prostituição, sexo, gênero e cultura no Brasil. Rio de Janeiro: Editora Fiocruz, 2008.

LAGO, Natália; ZAMBONI, Marcio. "Políticas sexuais e afetivas da prisão: gênero e sexualidade em contextos de privação de liberdade". Anais do 40 Encontro Anual da Anpocs, vol. 40, Caxambu: Anpocs, 2016, pp. 1-25.

LOURENÇO, Luiz Claudio. "Contribuições pioneiras das ciências sociais no estudo sobre as prisões brasileiras do séc. XX”. Vivência: Revista de Antropologia, n. 46, pp. 169-180, 2015.

LOURO, Guacira Lopes. “Gênero e sexualidade: Pedagogias contemporâneas”. Pro-Posições, vol. 19, n. 2, pp. 17-23, 2008.

MARQUES, Adalton. Crime, proceder, convívio-seguro: Um experimento antropológico a partir de relações entre ladrões. Dissertação (Mestrado em Antropologia Social) - Universidade de São Paulo, São Paulo, 2009.

MARQUES, Roberto. "Embaralhando Nordestes: Produção de sujeitos, tempos e espaços nas narrativas de João do Crato”. Amazônica: Revista de Antropologia, vol. 8, n. 2, pp. 456 - 478, 2016.

MARQUES, Roberto; FEITOSA, Antonio Lucas Cordeiro; PALMEIRA, Lucas. "Incorporando o Estado em bairros periféricos: Risco e mediação em Equipes de Saúde da Família”. Anais do 
IV Seminário Internacional Violência e Conflitos Sociais: Territorialidades e Negociações. Fortaleza: EdUFC, 2014, pp. 1-10.

NASCIMENTO, Francisco Elionardo de Melo. “Por bem menos se interdita um zoológico': Apontamentos da condição histórica das prisões cearenses que culminou na crise penitenciária”. Aracê: Direitos Humanos em Revista, vol. 4, n. 5, pp. 136-159, 2017.

NASCIMENTO, Francisco Elionardo de Melo. Travestilidades aprisionadas: Narrativas de experiências de travestis em cumprimento de pena no Ceará. Dissertação (Mestrado em Sociologia) - Universidade Estadual do Ceará, Fortaleza, 2018a.

NASCIMENTO, Francisco Elionardo de Melo. "A inscrição do feminino no corpo travesti: A trajetória das transformações da travestilidade de Renata”. História e Cultura, vol. 7, n. 1, pp. 221-237, 2018 b.

NASCIMENTO, Francisco Elionardo de Melo. “'A gente já nasce travesti': O processo de transformações das travestilidades e violências nas narrativas de travestis aprisionadas no Ceará”. Ponto Urbe, vol. 23, pp. 1-17, 2018 c.

NASCIMENTO, Francisco Elionardo de Melo. "Pesquisa e trabalho no cárcere: desafios da pesquisa e do trabalho dos agentes penitenciários na prisão". Vivência: Revista de Antropologia, vol. 1, n. 51, pp. 180-201, 2018d.

NASCIMENTO, Francisco Elionardo de Melo. "Agente penitenciário e/ou pesquisador? Trabalho e pesquisa na prisão desde um lugar relacional”. Revista Norus: Novos Rumos Sociológicos, vol. 6, n. 10, pp. 304-327, 2018e.

NASCIMENTO, Francisco Elionardo de Melo. "Agrupamento de travestis e transexuais encarceradas no Ceará”. Revista Estudos Feministas, vol. 28, n. 1, e57687, 2020.

NASCIMENTO, Francisco Elionardo de Melo; FREITAS, Geovani Jacó. "Faç̧ões, rebeliões, violência e gestão do aprisionamento do Ceará”. O público e o privado, n. 33, jun/jul, pp. 143-166, 2019.

PADOVANI, Natália Corazza. "No olho do furacão: Conjugalidades homossexuais e o direito à visita íntima na Penitenciária Feminina da Capital”. Cadernos Pagu, vol. 37, pp. 185-218, 2011.

PELÚCIO, Larissa. Abjeção e desejo: Uma etnografia travesti sobre o modelo preventivo de AIDS. São Paulo: Annablume, 2009.

PISCITELLI, Adriana. "Interseccionalidades, categorias de articulação e experiências de migrantes brasileiras". Sociedade e Cultura, vol. 11, n. 2, pp. 263-274, 2008.

RAPPORT, Nigel. "Individuality”. In: RAPPORT, Nigel; OVERING, Joanna. Social and Cultural Anthropology: The Key Concepts. Londres: Routledge, 2000, pp. 185-195.

SÁ, Leonardo Damasceno; AQUINO, Jania Perla Diógenes de. “'Guerra das facções’ no Ceará (2013-2018): Socialidade armada e disposição viril para matar ou morrer”. Anais do $42^{\circ}$ Encontro Anual da Anpocs, vol. 42, Caxambu, 2018, pp. 1-30.

SALIH, Sarah. Judith Butler e a teoria queer. Belo Horizonte: Autêntica, 2013.

SIQUEIRA, Ítalo Barbosa Lima; PAIVA, Luiz Fábio Silva. "'No Norte tem Comando': As contradições e os efeitos políticos do encarceramento em massa". Anais do $18^{\circ}$ Congresso Brasileiro de Sociologia, vol. 18, Brasília, 2017, pp. 1-21. 
SIMÕES, Júlio Assis; FRANÇA, Isadora Lins; MACEDO, Macio. "Jeitos de corpo: Cor/raça, gênero, sexualidade e sociabilidade juvenil no centro de São Paulo”. Cadernos Pagu, vol. 35, pp. 37-78, 2010.

WACQUANT, Loïc. As prisões da miséria. Rio de Janeiro: Zahar, 2001.

$\begin{array}{ll}\text { FRANCISCO } & \text { ELIONARDO DE MELO } \\ \text { NASCIMENTO } & \text { (elionardomelo@gmail.com) é }\end{array}$ agente penitenciário na Secretaria de Administração Penitenciária do Ceará (Sap/CE, Sobral, Brasil) e professor da Faculdade leducare (Fied) do Centro Universitário Inta (Uninta, Tianguá, Brasil). É doutorando do Programa de Pós-Graduação em Sociologia (PPGS) da Universidade Estadual do Ceará (Uece, Fortaleza, Brasil) e mestre pelo mesmo programa.

https://orcid.org/0000-0003-1781-8717

ROBERTO MARQUES (enleio@yahoo.com.br) é professor do Departamento de Ciências Sociais da Universidade Regional do Cariri (Urca, Crato, Brasil) e do PPGS da Uece. Tem doutorado pelo Programa de Pós-Graduação em Sociologia e Antropologia (PPGSA) da Universidade Federal do Rio de Janeiro (UFRJ, Rio de Janeiro, Brasil), com estágio pós-doutoral na mesma instituição e na Universidade Estadual de Campinas (Unicamp, Brasil). É mestre pelo Programa de PósGraduação em Sociologia (PPGS) da Universidade Federal da Paraíba (UFPB, João Pessoa, Brasil) e graduado em psicologia pela Universidade Federal do Ceará (UFC, Fortaleza, Brasil).

\section{https://orcid.org/0000-0002-5494-6462}

MARIA DO SOCORRO FERREIRA OSTERNE (socorro.osterne@uece.br) é livre docente do Departamento de Serviço Social da Uece, professora do Mestrado Acadêmico em Serviço Social, Trabalho e Questão Social (MASS) e do Programa de Pós-Graduação em Planejamento e Políticas Públicas (PPGPP) e professora colaboradora do PPGS, todos da Uece. É doutora pelo Programa de Pós-Graduação em Serviço Social (PPGSS) da Universidade Federal de Pernambuco (UFPE, Recife, Brasil) e mestre pelo Programa de Pós-Graduação em Sociologia (PPGS) da UFC.

https://orcid.org/0000-0001-5627-6784 